\title{
Observed Concentration Budgets of Arctic and Antarctic Sea Ice
}

\author{
PAUl R. HOLLAND \\ British Antarctic Survey, Cambridge, United Kingdom \\ NORIAKI KIMURA \\ Atmosphere and Ocean Research Institute, The University of Tokyo, Tokyo, Japan
}

(Manuscript received 8 February 2016, in final form 19 May 2016)

\begin{abstract}
In recent decades, Antarctic sea ice has expanded slightly while Arctic sea ice has contracted dramatically. The anthropogenic contribution to these changes cannot be fully assessed unless climate models are able to reproduce them. Process-based evaluation is needed to provide a clear view of the capabilities and limitations of such models. In this study, ice concentration and drift derived from AMSR-E data during 2003-10 are combined to derive a climatology of the ice concentration budget at both poles. This enables an observational decomposition of the seasonal dynamic and thermodynamic changes in ice cover. In both hemispheres, the results show spring ice loss dominated by ice melting. In other seasons ice divergence maintains freezing in the inner pack while advection causes melting at the ice edge, as ice is transported beyond the region where it is thermodynamically sustainable. Mechanical redistribution provides an important sink of ice concentration in the central Arctic and around the Antarctic coastline. This insight builds upon existing understanding of the sea ice cycle gained from ice and climate models, and the datasets may provide a valuable tool in validating such models in the future.
\end{abstract}

\section{Introduction}

Satellites have played a key role in monitoring decadal changes in the sea ice cover, most notably in the passive microwave record of near-daily ice concentration fields since 1978. During this period, Antarctic sea ice has expanded slightly while Arctic sea ice has contracted dramatically (Parkinson 2014). These high-profile changes raise many questions: Are they anthropogenic or natural? What is the role of ice-climate feedbacks? Why are the two poles so different? Are the changes predominantly dynamic or thermodynamic in origin?

Such questions can be answered using a climate model, but only if its capabilities and limitations are

Supplemental information related to this paper is available at the Journals Online website: http://dx.doi.org/10.1175/ JCLI-D-16-0121.s1.

Corresponding author address: Paul Holland, British Antarctic Survey, High Cross, Madingley Road, Cambridge, CB3 0ET, United Kingdom.

E-mail: p.holland@bas.ac.uk understood. In the Arctic, CMIP5 models typically feature a slower decline than observed (Stroeve et al. 2012). In the Antarctic, the models produce ice loss of a similar magnitude to the Arctic, in contrast to observations (Zunz et al. 2013). However, in both hemispheres the range of CMIP5 simulations does encompass the observed trends. Free-running ice-ocean models forced by atmospheric reanalyses can reproduce the trends in detail (Holland et al. 2014; Lindsay et al. 2009). However, the reanalyses use ice observations in their surface boundary conditions, fixing a "shadow" of the ice cover into the near-surface atmospheric fields. The forced model has to match these fields, and so could produce the right ice extent for the wrong reason. Models that assimilate data can achieve an excellent fit to observations (Massonnet et al. 2013; Schweiger et al. 2011), but most introduce unphysical corrections that do not satisfy the underlying model equations. In all cases, state variables such as ice extent can match observations even though the processes governing that variable are incorrect; models may contain compensating errors.

This study combines ice concentration and drift data to map the observed dynamic and thermodynamic 
contributions to the seasonal cycle of ice concentration at both poles (Holland and Kwok 2012). This offers insight into the processes governing the ice cover and can also be useful in diagnosing model failings by revealing compensating errors (Lecomte et al. 2016, manuscript submitted to Ocean Modell.; Uotila et al. 2014). For example, Uotila et al. (2014) showed that their model had a realistic seasonal cycle in Antarctic ice extent despite underestimating thermodynamic ice growth by a factor of 3; this error was compensated by excessive ice advection.

Previous studies have decomposed the ice volume and concentration budgets in model results, yielding significant insight into seasonal and decadal changes (e.g., Holland et al. 2010). In both hemispheres, ice growth is sustained by divergence from coastlines, and melting occurs at the ice edge as ice is advected beyond the region where it is thermodynamically sustainable (Bitz et al. 2005; Lindsay and Zhang 2005). Modeled ice trends at both poles have also been divided into their dynamic and thermodynamic components (Holland et al. 2014; Lindsay and Zhang 2005). This study aims to provide observational evidence to validate such studies.

\section{Method}

Changes in ice concentration are caused by dynamic and thermodynamic processes, which we separate using the technique of Holland and Kwok (2012) to decompose the governing equation for ice concentration:

$$
\frac{\partial C}{\partial t}+\nabla \cdot(\mathbf{u} C)=f_{C}-r .
$$

We refer to $\partial C / \partial t$ as ice "intensification" (Holland 2014). Intensification and ice concentration flux divergence on the left-hand side of this equation are determined by combining satellite-derived ice concentration $(C)$ and drift (u), and the total residual on the right-hand side represents thermodynamic melting/freezing $\left(f_{C}\right)$ and mechanical redistribution $(r)$. The latter refers to massconserving processes such as ridging and rafting that thicken the ice at the expense of ice concentration, and is hereafter referred to as "ridging" for simplicity. It is instructive to separate the flux divergence into "advection" and "divergence," so the data are used to determine four terms:

$$
\frac{\partial C}{\partial t}=-\mathbf{u} \cdot \nabla C-C \nabla \cdot \mathbf{u}+\text { residual },
$$

where the residual combines thermodynamics and ridging. We adopt the sign convention that positive values of all terms are associated with an increase in ice cover.
We apply this methodology using daily ice concentration derived from AMSR-E brightness temperatures on a $12.5-\mathrm{km}$ grid using the Enhanced NASA Team algorithm (Cavalieri et al. 2014). Ice drift is derived using a cross-correlation technique (Kimura and Wakatsuchi 2011; Kimura et al. 2013) applied to AMSR-E brightness temperatures at $10-\mathrm{km}$ resolution. This results in daily drift fields at $60-\mathrm{km}$ resolution, so concentration data are binned onto this grid to derive budget terms. Antarctic ice drift and wintertime Arctic drift are derived using 36-GHz channels, while Arctic summertime drift (April-October) are derived using 18-GHz channels to maximize data quality and coverage (Kwok 2008). Noise in ice drift fields is amplified in the divergence term, so we smooth ice drifts with a $7 \times 7$ cell squarewindow filter.

Mean seasonal ice concentration and drift from these data products are shown in Figs. 1 and 2. Many other datasets are available, and the different products have been intercompared in several previous studies (e.g., Ivanova et al. 2015; Sumata et al. 2015). In the supplementary material we assess the uncertainty in our budgets by recalculating them using different ice concentration and drift datasets. Our reference datasets are chosen on the basis that they offer high-resolution yearround coverage at both poles for sufficient years to calculate a budget climatology.

For each day, intensification is calculated as a central difference in time between concentration fields from the day after and the day before, while advection and divergence are calculated daily using central differences in space and then averaged over the same 3-day period to obtain a consistent time stamp. The residual in (2) is the difference of these three terms. The terms are calculated daily for all whole years that AMSR-E operated, 200310 , and the daily data are then averaged together to create a seasonal climatology for each pole (Figs. 3 and 4). For consistency between poles, seasons are defined such that winter is centered on the month of maximum ice area in each hemisphere. Since the Antarctic spring ice contraction is faster than its autumn expansion, the Antarctic "summer" season defined here actually includes a month of ice growth (April).

The tracking procedure does not capture drift near the ice edge, so we can only decompose the concentration budget for intensification in the interior ice pack. The neglected intensification is only a small fraction of the intensification calculated from all ice concentration data. This neglected intensification also has identical spatial patterns to the interior intensification, so we believe that our budget decomposition is applicable throughout. Nevertheless, it is important to emphasize that the intensification shown in Figs. 3 and 4 is incomplete; it is the 


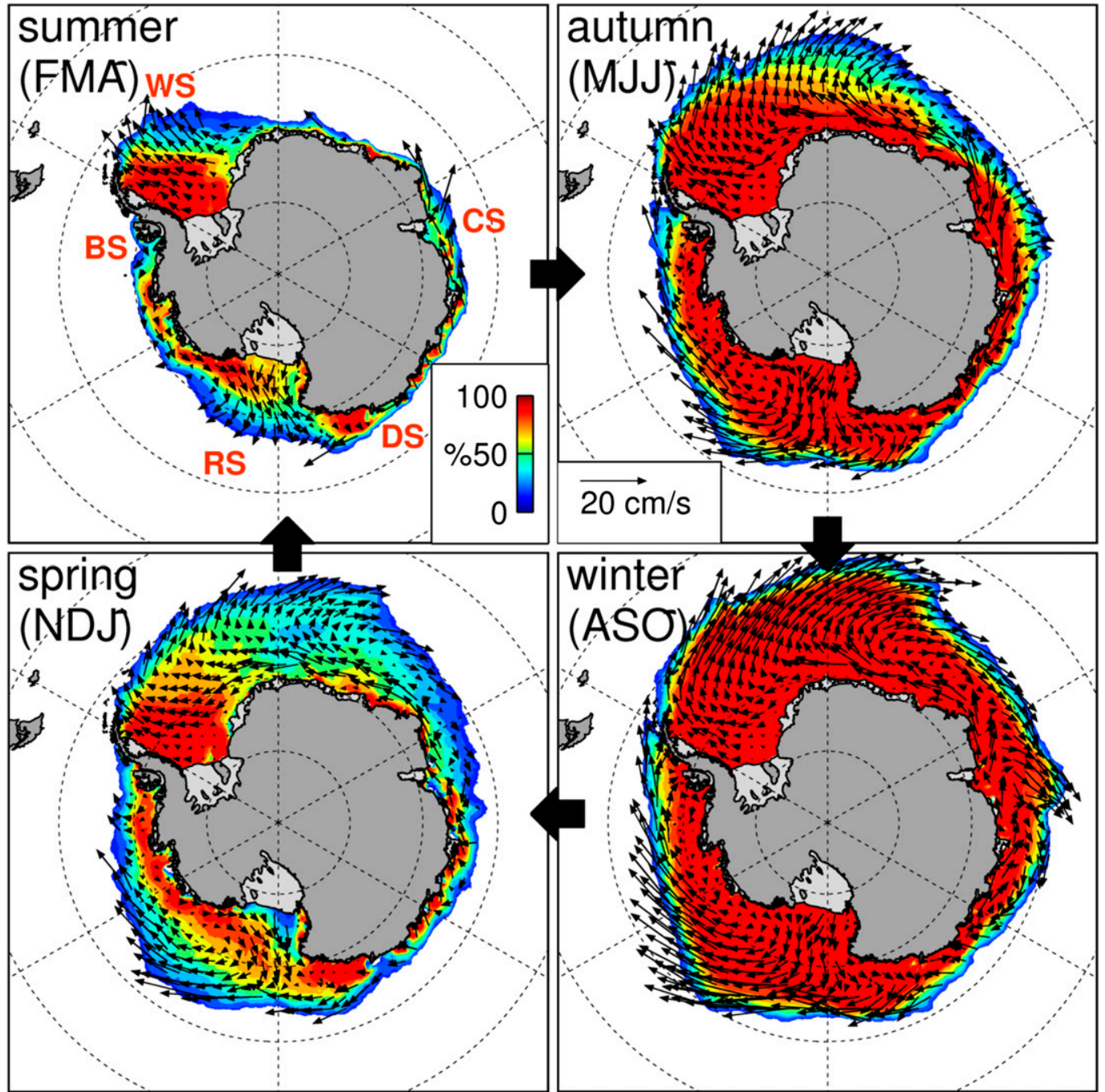

FIG. 1. Seasonal mean Antarctic sea ice concentration and drift calculated from AMSR-E data for 2003-10. Drift vectors are shown every third data point. WS-Weddell Sea; CS-Cooperation Sea; DS-Dumont D'Urville Sea; RSRoss Sea; BS-Bellingshausen Sea.

average of only the $\partial C / \partial t$ for which we have sufficient ice concentration and drift data to calculate all terms in the budget. The ice drift data are missing only at the ice edge, but this can affect the budgets everywhere because the ice edge moves through the seasonal mean fields.

\section{Results}

\section{a. Antarctic}

We consider first the Antarctic ice concentration budget (Fig. 3). The top row shows intensification $(\partial C / \partial t)$, which is the sum of the other three rows. Little intensification occurs in winter as a result of our definition of the seasons. The ice recedes rapidly in spring and expands more slowly in summer and autumn. In all seasons, advection $(-\mathbf{u} \cdot \nabla C)$ causes intensification in areas of strong ice transport down concentration gradients, such as the Ross, Weddell, and Cooperation Seas (Fig. 1). In winter, advection weakly opposes expansion in the Bellingshausen and Dumont D'Urville Seas, which experience an ice concentration source from convergence (a positive value of the divergence term $-C \nabla \cdot \mathbf{u}$ ). In most regions, divergence causes an ice concentration sink in the inner pack throughout the year.

The residual represents the net concentration source from thermodynamics and ridging. It is complex to interpret because concentration gain by freezing is offset by concentration loss from melting or ridging, and the residual reflects the net change during a season. A positive (negative) residual measures the amount by which total freezing is larger (smaller) than total melting and 


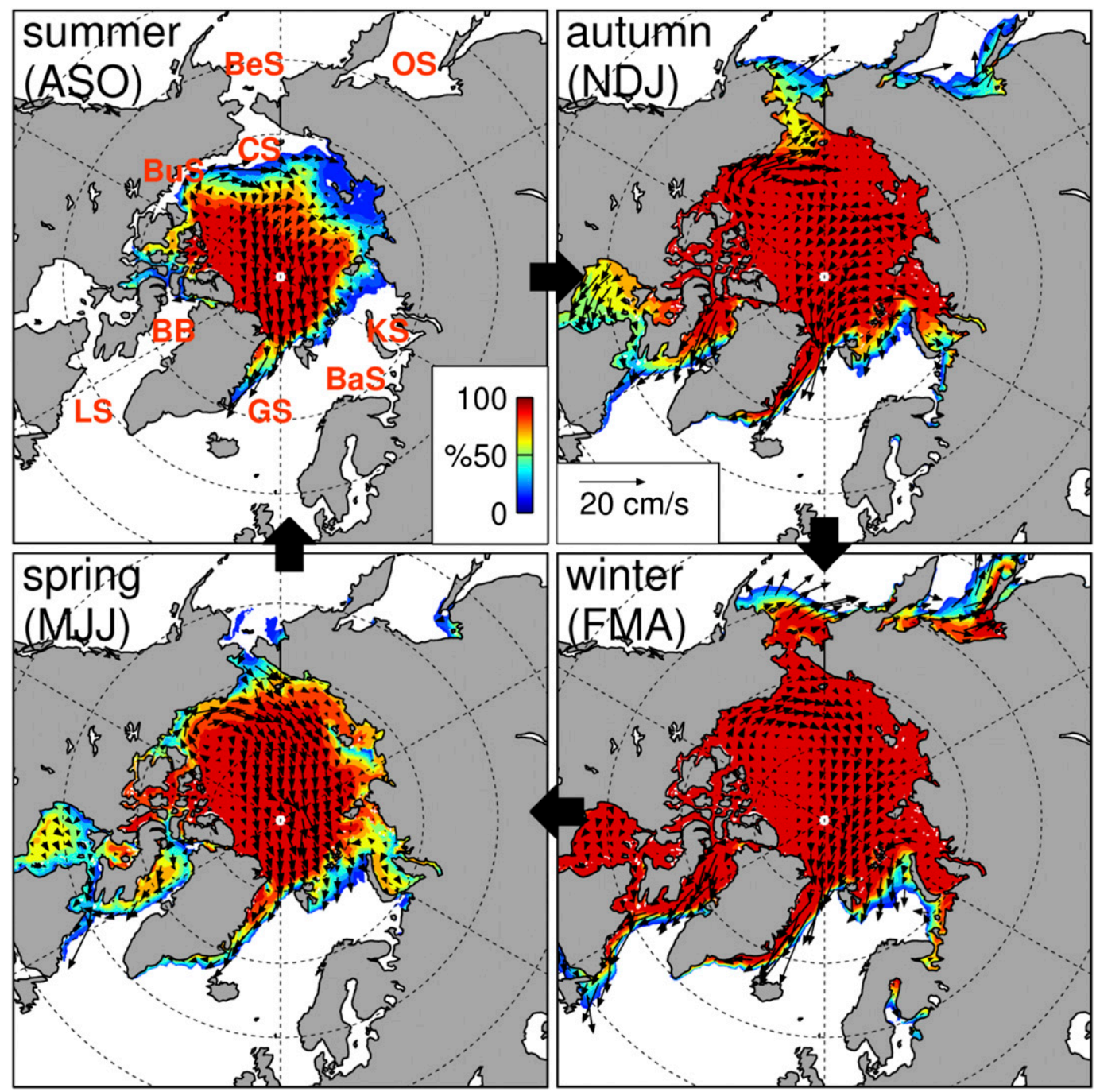

FIG. 2. As in Fig. 1, but for Arctic sea ice. BeS-Bering Sea; OS-Sea of Okhotsk; CS-Chukchi Sea; KS-Kara Sea; BaS-Barents Sea; GS-Greenland Sea; LS-Labrador Sea; BB-Baffin Bay; BuS-Beaufort Sea.

ridging. We argue that ridging may only dominate where the residual is negative (a concentration sink), ice drift is convergent, and ice concentration is high $(>90 \%)$. Magenta contours in Fig. 3 encircle areas that satisfy these criteria, suggesting that thermodynamics overwhelmingly dominates the residual. During summer, autumn, and winter, the residual is largely a concentration source, implying a dominance of freezing. This freezing is partly related to intensification (increase in ice concentration) and partly related to divergence (maintenance of existing ice cover). The negative residual in spring represents melting, since ice drift is divergent and concentration is low (Fig. 1). Negative ice-edge residuals in autumn and winter largely represent melting, despite some convergence where ridging may dominate. This melting suggests that ice drifts equatorward beyond the region where it is thermodynamically sustainable, as determined by meridional gradients in ocean properties and incoming radiation (Bitz et al. 2005; Martinson and Iannuzzi 1998). Areas of negative residual also occur near the coast in autumn and winter in the Ross, Bellingshausen, and Weddell Seas and East Antarctica. These are areas of convergence within a full ice cover during cold seasons, so the residual is dominated by ridging as ice is compressed against the coast (Uotila et al. 2014).

For both poles, Fig. 5 shows the mean annual cycle in total ice area (the integral of ice concentration $C$; units are $10^{6} \mathrm{~km}^{2}$ or $\mathrm{Mkm}^{2}$ ), ice expansion (the area integral of intensification $\partial C / \partial t ; \mathrm{Mkm}^{2} \mathrm{yr}^{-1}$; Holland 2014), and the thermodynamic and dynamic constituents of expansion. The daily budget terms are first averaged into a monthly climatology, and then these monthly fields are 


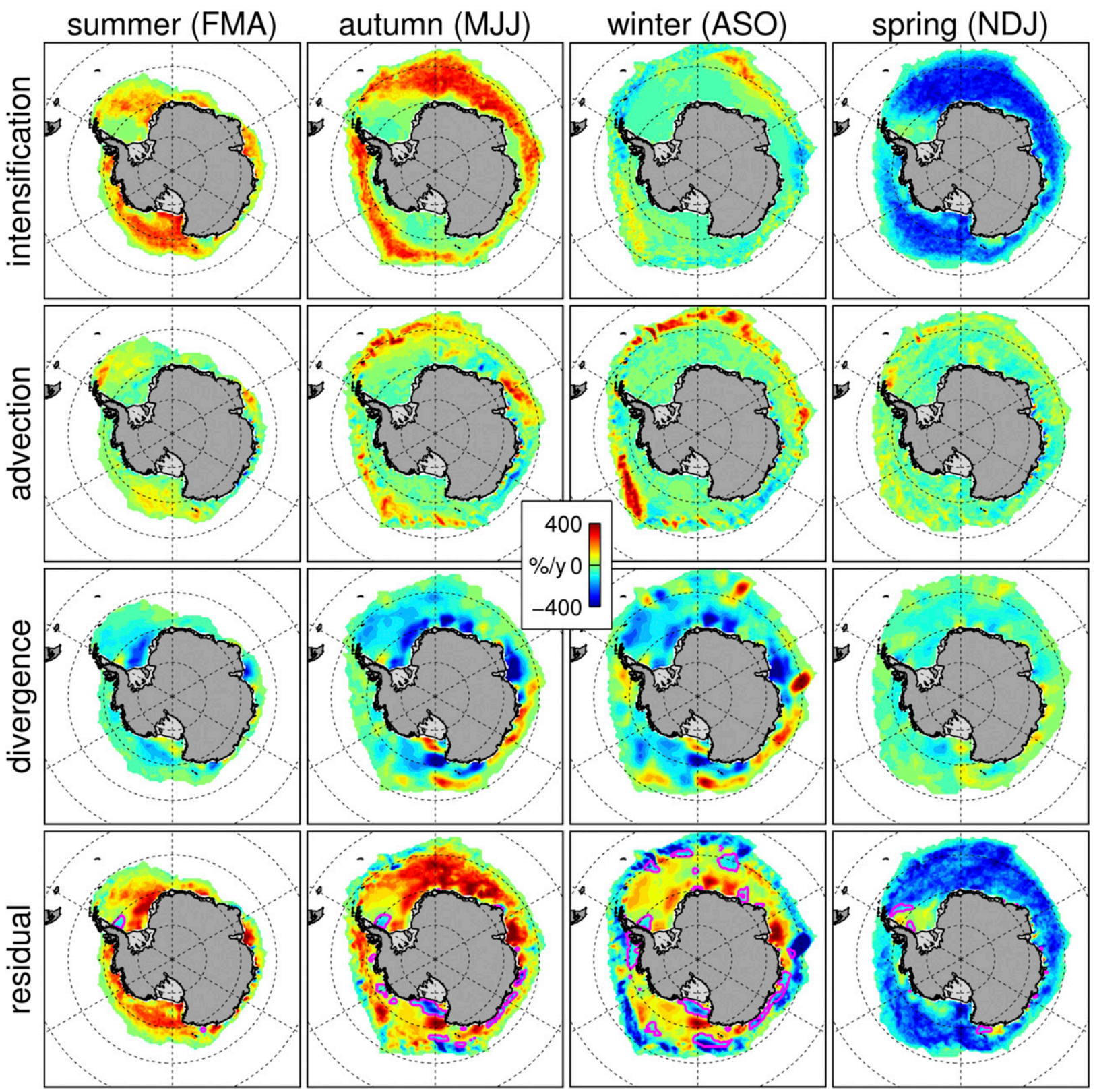

FIG. 3. Components of the seasonal mean Antarctic sea ice concentration budget for 2003-10. See sections 2 and 3 for a full description of the terms. The rows are seasonal means of: intensification $(\partial C / \partial t)$; advection $(-\mathbf{u} \cdot \nabla C)$; divergence $(-C \nabla \cdot \mathbf{u})$; residual (thermodynamics and ridging). The top row is the sum of other rows. The sign convention is that all positive terms are a source of ice. Colors saturate when ice appears or disappears completely within a season ( $100 \%$ concentration change over one quarter of a year). The magenta contour in the bottom row encircles areas where ridging may dominate the residual according to the criteria of negative residual (a concentration sink), convergent ice drift, and concentration $>90 \%$.

spatially integrated. Integrated over the hemisphere, expansion should equal the residual (primarily thermodynamics) because the dynamic terms integrate to zero; lateral transports redistribute ice concentration but do not create or destroy it. Therefore, to illustrate the magnitude of ice transports, we plot area integrals of the positive $(\mathrm{dy}+)$ and negative $(\mathrm{dy}-)$ parts of the ice concentration flux divergence $-\nabla \cdot(\mathbf{u} C)$ (the sum of advection and divergence). There is a small difference between expansion and residual in our calculations (hence an inequality between $\mathrm{dy}+$ and $\mathrm{dy}-$ ) because inaccuracy and missing values in the source data imply a net convergence or divergence on hemispheric integration. 


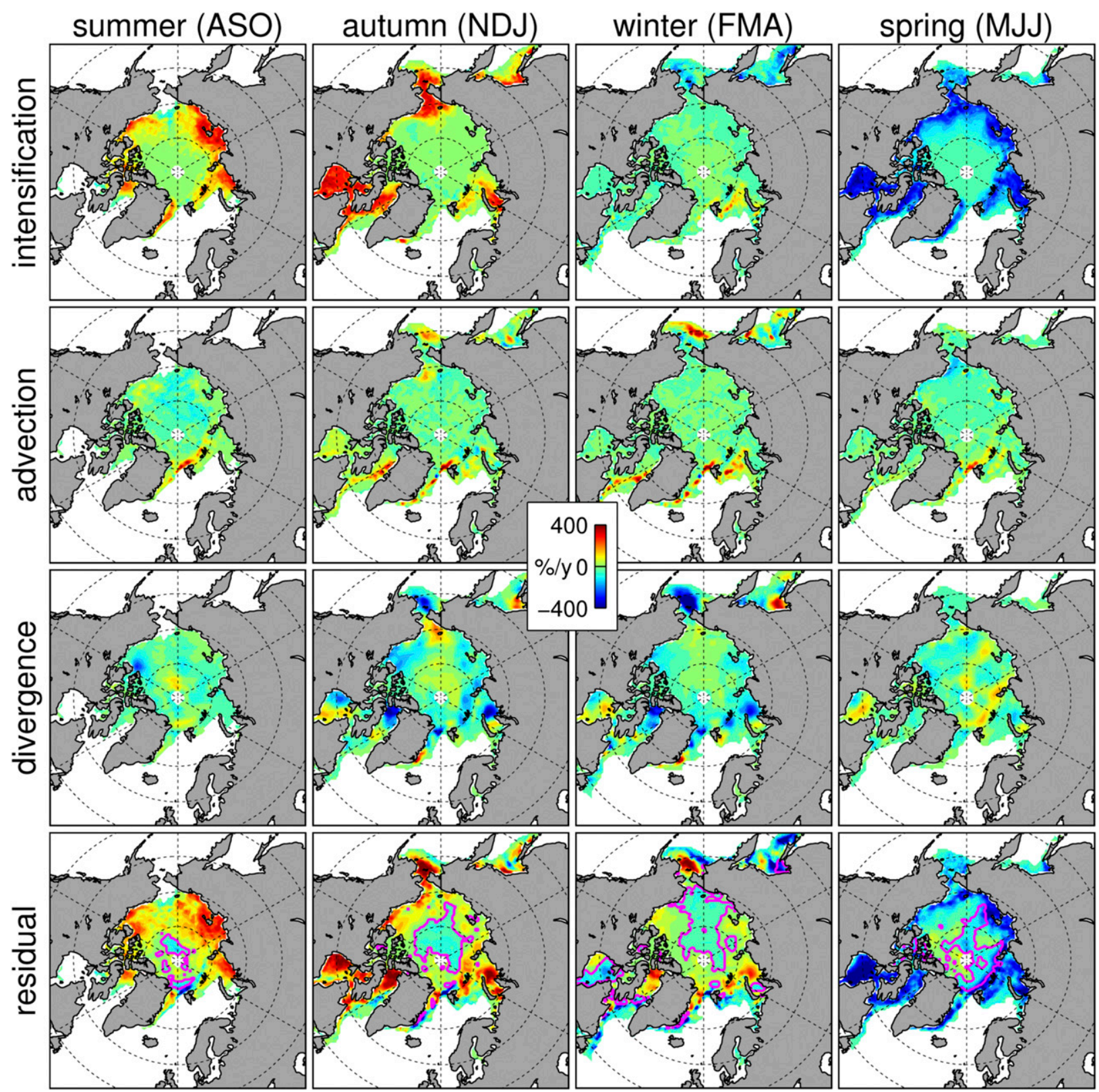

FIG. 4. As in Fig. 3, but for Arctic sea ice.

In Antarctica, relatively slow thermodynamic expansion occurs for an extended period in summer and autumn, while relatively rapid thermodynamic contraction occurs in spring. Dynamic transports follow the same cycle as ice area, strongest in autumn and winter when ice concentration and its gradients are highest and ice drift and its divergence are strongest (Figs. 1 and 3). Dynamic transports are important in nonsummer months and larger than thermodynamic expansion during winter. Figure 5 also shows that the interannual variability of all terms is a small fraction of their mean value.
It is informative to compare the modeled ice volume budget of Bitz et al. (2005) to our observed concentration budget. Modeled spring ice loss is also dominated by thermodynamics, with autumn and winter growth controlled by freezing and dynamics. The model has a source at the ice edge due to convergence, but proportionately less net melting there than our observed budgets. This could be a difference between concentration and volume budgets, or ambiguity in our residual. The model has rapid divergence-led ice growth in a band encircling the Antarctic coast, which does not appear in our budget. In reality, Antarctica is surrounded by small, localized 


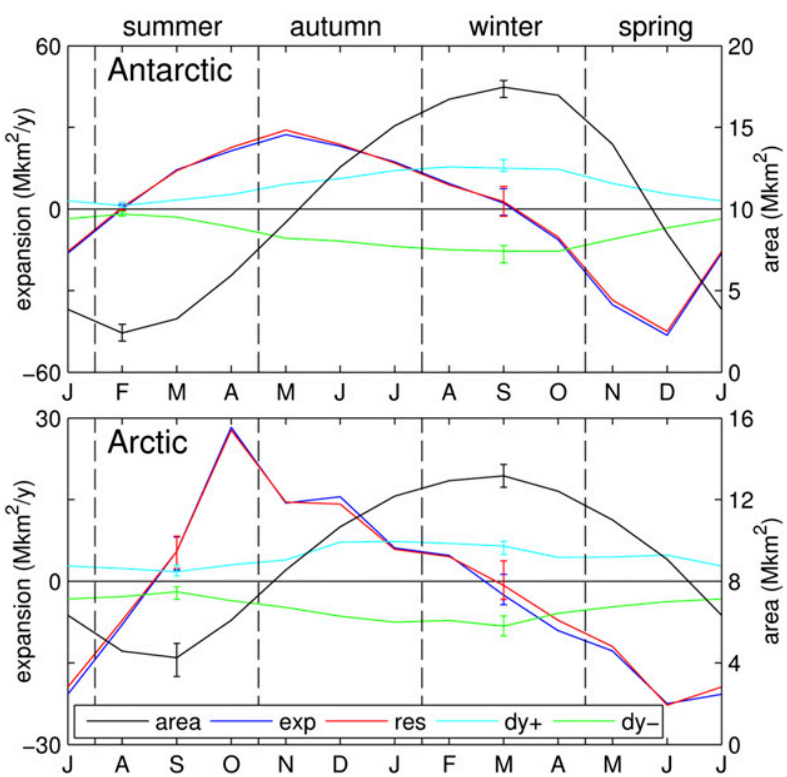

FIG. 5. Monthly climatologies of ice area (right axis) and the ice concentration budget (left axis) integrated over each hemisphere. See sections 2 and 3 for a full description of the terms. Area: total ice area (integral of $C$ ); exp: expansion (integral of $\partial C / \partial t$ ); res: integral of residual (primarily thermodynamic change); dy $+/ \mathrm{dy}-$ : spatial integrals of the positive and negative parts of ice concentration flux divergence $-\nabla \cdot(\mathbf{u} C)$. Note the differences in scale between poles. Error bars show the range of interannual variability within the record at the summer minimum and winter maximum.

polynyas that extend up to $\sim 100 \mathrm{~km}$ from the coast (Tamura et al. 2008) and are therefore not resolved by our budget calculations.

\section{b. Arctic}

The Arctic ice cover also melts rapidly in spring and expands in late summer and autumn (Figs. 4 and 5). Advection extends the ice equatorward at the ice edge, most notably in the Bering and Barents Seas and the East Greenland and Labrador Currents, which are only marginally resolved (Fig. 2). Persistent strong divergence occurs in many regions, including the Beaufort, Bering, and Kara Seas, northwest Greenland, and Baffin Bay, primarily in autumn and winter.

The residual fields are consistent with a dominance of ridging in the central Arctic, surrounded by thermodynamic change in the seasonal ice zone. The central Arctic features high ice concentrations and weak convergence $\left(\sim 50 \% \mathrm{yr}^{-1}\right)$, which implies a residual ice sink of the same magnitude. Since it is unlikely that this sink represents melting in winter, we attribute it to a dominance of ridging. Ridging may also be dominant in fast-moving ice around the margin, such as north of Svalbard and east of Greenland. Elsewhere the residual is clearly dominated by thermodynamics, with widespread melting in spring and freezing in other seasons. In common with the Antarctic, equatorward advection is associated with melting.

Our observed Arctic ice concentration budget is broadly consistent with the model ice volume budgets of Bitz et al. (2005) and Lindsay and Zhang (2005), which show freezing near coastlines and dynamic ice fluxes and melting at unbounded ice edges. Bitz et al. (2005) conclude that ocean heat content is a major limitation on the ice edge in the Greenland and Barents seas, which is consistent with our derivation of year-round melting in these regions. We again expect our budget to miss important polynyas around the coastline, which appear in the models. There is also significant thermodynamic ice thickening in the modeled ice pack, which will not be manifest in our concentration budgets.

The Arctic ice cover and its expansion rate are smaller than their Antarctic counterparts, and more symmetrically distributed through the year (Fig. 5). The rate of expansion varies during autumn as the ice edge interacts with landmasses (Figs. 4 and 5). Dynamic transports feature a background level of convergence in the central Arctic throughout the year, increasing in magnitude in late autumn and winter when the equatorward boundary currents are strongest (Fig. 2).

\section{Conclusions}

This study presents the first observed seasonal climatology of the sea ice concentration budget at both poles. In both hemispheres, ice dynamics are less important during spring, when melting dominates the concentration budget, but in other seasons dynamics become more important and ice is advected significantly beyond the region where it is thermodynamically sustainable. In the inner pack, freezing is sustained by ice divergence. In the Antarctic, equatorward transport creates zonal bands of freezing to the south and melting to the north, while the Arctic hosts freezing at higher latitudes and melting in southward coastal currents. Some of these features have been previously demonstrated in model ice volume budgets, so this study provides an observational validation and extension of those results. We also find that the overall strength of dynamic ice transport follows the seasonal variation of ice area, peaking in winter, while thermodynamic expansion is the temporal derivative of ice area and therefore peaks in autumn and spring. Mechanical redistribution provides the dominant sink of ice concentration around the Antarctic coastline and in the central Arctic. The supplementary information assesses the uncertainty in the derived budgets by repeating the calculations with different datasets for ice concentration and drift. The conclusions are found to be robust to this change. 


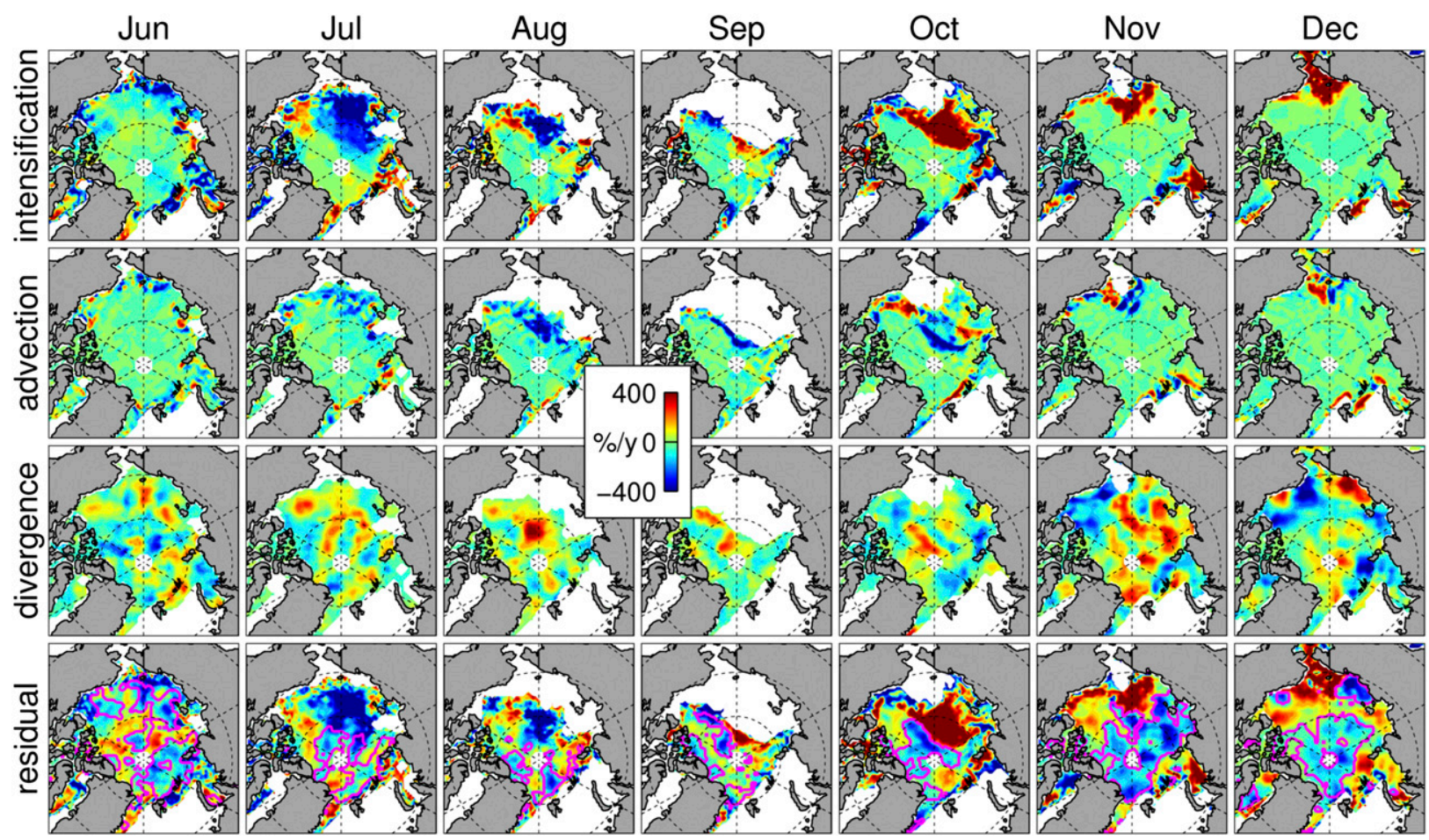

FIG. 6. Arctic concentration budget anomalies in the summer of 2007. For each budget component for each month, the panel shows the values in 2007 minus the 2003-10 mean. The magenta contour in the bottom row encircles areas where ridging may dominate the residual according to the criteria of negative residual, convergent drift, and concentration $>90 \%$; these criteria are applied to the full monthly fields, not anomalies.

The results have several important implications. Derived thermodynamic changes identify an observational map of the locations of brine rejection and meltwater input that provide buoyancy forcing to the world's oceans. Derived boundaries between wintertime freezing and melting are dictated by ocean and atmospheric heat fluxes (Bitz et al. 2005; Martinson and Iannuzzi 1998), and the ice edge is governed by advection across this line. Perhaps the most important future use for these data lies in the quantitative comparison of observed and modeled ice concentration budgets. If modeled ice concentration fields do not match observations, our budget data can be used to isolate the origin of the problem within seasonally varying dynamic and thermodynamic processes. The technique can also identify where model agreement with observations is a result of compensating errors (Lecomte et al. 2016, manuscript submitted to Ocean Modell; Uotila et al. 2014).

The short period of AMSR-E data means we cannot examine long-term trends, but we can consider anomalies within the record. We use the 2007 Arctic summer minimum as a test case to determine the minimum averaging period over which a useful budget signal appears. During this anomaly, anticyclonic winds over the Canada Basin drove significant ice loss. Observations
(Kwok 2008) and model budgets (Lindsay et al. 2009; Zhang et al. 2008) show that thermodynamic forcing accounted for $70 \%-85 \%$ of the ice area loss. Monthlymean budget anomalies (Fig. 6) are consistent with this explanation, with a strong correspondence between intensification and residual anomalies in a region where the residual is governed by thermodynamics. Advective anomalies occur during July-October, but are offset locally by convergence. Ice velocity divergence provides the largest source of noise in these anomalies, and indeed in the climatological fields. Since the summer 2007 minimum is one of the largest anomalies on record, and its decomposition is still only marginally captured by the method, we regard one month as being the shortest averaging period over which the budget decomposition contains a useful signal.

All of our conclusions are limited by the fact that this is an ice concentration, not volume, budget. This complicates the interpretation of the residual and precludes any quantification of accompanying freshwater fluxes. The ultimate aim of this work must be to observationally distinguish dynamic and thermodynamic ice volume trends at both poles, a task that remains challenging due to the limited coverage of ice thickness and drift observations. 


\section{REFERENCES}

Bitz, C. M., M. M. Holland, E. C. Hunke, and R. E. Moritz, 2005: Maintenance of the sea-ice edge. J. Climate, 18, 2903-2921, doi:10.1175/JCLI3428.1.

Cavalieri, D. J., T. Markus, and J. C. Comiso, 2014: AMSR-E/Aqua daily L3 $12.5 \mathrm{~km}$ brightness temperature, sea ice concentration, $\&$ snow depth polar grids, version 3. NASA National Snow and Ice Data Center Distributed Active Archive Center, accessed 20 February 2015, doi:10.5067/AMSR-E/AE_SI12.003.

Holland, M. M., M. C. Serreze, and J. Stroeve, 2010: The sea ice mass budget of the Arctic and its future change as simulated by coupled climate models. Climate Dyn., 34, 185-200, doi:10.1007/s00382-008-0493-4.

Holland, P. R., 2014: The seasonality of Antarctic sea ice trends. Geophys. Res. Lett., 41, 4230-4237, doi:10.1002/2014GL060172.

—_, and R. Kwok, 2012: Wind-driven trends in Antarctic sea-ice drift. Nat. Geosci., 5, 872-875, doi:10.1038/ngeo1627.

_, N. Bruneau, C. Enright, N. T. Kurtz, M. Losch, and R. Kwok, 2014: Modeled trends in Antarctic sea ice thickness. J. Climate, 27, 3784-3801, doi:10.1175/JCLI-D-13-00301.1.

Ivanova, N., and Coauthors, 2015: Inter-comparison and evaluation of sea ice algorithms: Towards further identification of challenges and optimal approach using passive microwave observations Cryosphere, 9, 1797-1817, doi:10.5194/tc-9-1797-2015.

Kimura, N., and M. Wakatsuchi, 2011: Large-scale processes governing the seasonal variability of the Antarctic sea ice. Tellus, 63A, 828-840, doi:10.1111/j.1600-0870.2011.00526.x.

_ A. Nishimura, Y. Tanaka, and H. Yamaguchi, 2013: Influence of winter sea-ice motion on summer ice cover in the Arctic. Polar Res., 32, 20193, doi:10.3402/polar.v32i0.20193.

Kwok, R., 2008: Summer sea ice motion from the $18 \mathrm{GHz}$ channel of AMSR-E and the exchange of sea ice between the Pacific and Atlantic sectors. Geophys. Res. Lett., 35, L03504, doi:10.1029/2007GL032692.

Lindsay, R. W., and J. Zhang, 2005: The thinning of Arctic sea ice, 1988-2003: Have we passed a tipping point? J. Climate, 18, 4879-4894, doi:10.1175/JCLI3587.1.

,-- A. Schweiger, M. Steele, and H. Stern, 2009: Arctic sea ice retreat in 2007 follows thinning trend. J. Climate, 22, 165176, doi:10.1175/2008JCLI2521.1.
Martinson, D. G., and R. A. Iannuzzi, 1998: Antarctic ocean-ice interaction: Implications from ocean bulk property distributions in the Weddell Gyre. Antarctic Sea Ice: Physical Processes, Interactions, and Variability, M. O. Jeffries, Ed., Amer. Geophys. Union, 243-271.

Massonnet, F., P. Mathiot, T. Fichefet, H. Goosse, C. K. Beatty, M. Vancoppenolle, and T. Lavergne, 2013: A model reconstruction of the Antarctic sea ice thickness and volume changes over 1980-2008 using data assimilation. Ocean Modell., 64, 67-75, doi:10.1016/j.ocemod.2013.01.003.

Parkinson, C. L., 2014: Global sea ice coverage from satellite data: Annual cycle and 35-yr trends. J. Climate, 27, 9377-9382, doi:10.1175/JCLI-D-14-00605.1.

Schweiger, A., R. Lindsay, J. L. Zhang, M. Steele, H. Stern, and R. Kwok, 2011: Uncertainty in modeled Arctic sea ice volume. J. Geophys. Res., 116, C00D06, doi:10.1029/ 2011JC007084.

Stroeve, J. C., V. Kattsov, A. Barrett, M. Serreze, T. Pavlova, M. Holland, and W. N. Meier, 2012: Trends in Arctic sea ice extent from CMIP5, CMIP3, and observations. Geophys. Res. Lett., 39, L16502, doi:10.1029/2012GL052676.

Sumata, H., R. Gerdes, F. Kauker, and M. Karcher, 2015: Empirical error functions for monthly mean Arctic sea-ice drift. J. Geophys. Res. Oceans, 120, 7450-7475, doi:10.1002/ 2015JC011151.

Tamura, T., K. I. Ohshima, and S. Nihashi, 2008: Mapping of sea ice production for Antarctic coastal polynyas. Geophys. Res. Lett., 35, L07606, doi:10.1029/2007GL032903.

Uotila, P., P. R. Holland, T. Vihma, S. J. Marsland, and N. Kimura, 2014: Is realistic Antarctic sea-ice extent in climate models the result of excessive ice drift? Ocean Modell., 79, 33-42, doi:10.1016/j.ocemod.2014.04.004.

Zhang, J. L., R. W. Lindsay, M. Steele, and A. Schweiger, 2008: What drove the dramatic retreat of Arctic sea ice during summer 2007? Geophys. Res. Lett., 35, L11505, doi:10.1029/ 2008GL034005.

Zunz, V., H. Goosse, and F. Massonnet, 2013: How does internal variability influence the ability of CMIP5 models to reproduce the recent trend in Southern Ocean sea ice extent? Cryosphere, 7, 451-468, doi:10.5194/tc-7-451-2013. 